\title{
El sildenafil fue un tratamiento seguro y efectivo para la disfunción sexual eréctil
}

Goldstein I, Lue TF, Padma-Nathan H et al for The Sildenafil in the treatment of erectile difunction.

\section{Objetivo}

Evaluar la eficacia y seguridad del sildenafil, en hombres con disfunción sexual eréctil (DSE) de causa orgánica, psicogénica o mixta.

\section{Diseño}

Dos estudios secuenciales: I) Dosis-respuesta, eficacia y seguridad: Ensayo randomizado, controlado con placebo y distintas dosis de sildenafil, con un seguimiento de 24 semanas. II) Ajuste de dosis, con extensión a largo plazo: ensayo randomizado, controlado, de 12 semanas de seguimiento. La dosis del sildenafil se ajustaba según éxito terapéutico o efectos adversos. A los pacientes que completaron las 12 semanas sin efectos adversos se les ofreció tratamiento con sildenafil por 32 semanas adicionales.

\section{Lugar}

Treinta y siete centros urológicos y sexológicos, EE.UU.

\begin{abstract}
Pacientes
Hombres $>18$ años con DSE y pareja estable de $\geq 6$ meses. Criterios de exclusión: defectos anatómicos peneanos; eyaculación precoz; injuria medular; trastorno psiquiátrico; diabetes no controlada; úlcera péptica; abuso de alcohol o drogas; alteraciones renales, hepáticas o hematológicas; infarto de miocardio o accidente cerebrovascular en los 6 meses previos; y estar recibiendo terapia con nitritos.
\end{abstract}

\section{Intervención}

Dosis-respuesta: placebo ( $n=216)$ vs. sildenafil en dosis fijas de 25 , 50 o $100 \mathrm{mg}(\mathrm{n}=316)$; una hora antes de mantener relaciones (dosis máxima: una por día). Se desaconsejaba beber más de dos tragos de alcohol en la hora previa.

Ajuste de dosis ( $n=329$ ) placebo o $50 \mathrm{mg}$ de sildenafil. En cada visita de seguimiento la dosis activa se duplicaba o reducía a la mitad en base a la respuesta terapéutica o efectos adversos.

\section{Medición de resultados principales}

Indice Internacional de Función Eréctil. La eficacia se evaluó específicamente con preguntas acerca del éxito en la penetración y el sostenimiento de la erección luego de la penetración en una escala de 1 a 5 (valores absolutos y porcentaje de cambio con respecto al basal).

\section{Resultados Principales}

El análisis fue por intención de tratar. En ambos estudios la causa principal de DSE fue orgánica (55-78\%), luego mixtas (13-31\%) y psicogénicas (9-16\%). El seguimiento fue mayor al $85 \%$ en ambos. Estudio dosis-respuesta: la dosis de sildenafil se asoció a mayor éxito en la penetración y mantención de erección $(p<0.001)$. El éxito aumentó un 60,84 y $100 \%$ en los que recibieron $25,50,100$ mg de sildenafil; en comparación con sólo un $5 \%$ en los que recibieron placebo. La función eréctil, orgásmica, satisfacción con la relación sexual y global también fueron superiores en los que recibieron sildenafil $(p<0.001)$. La proporción de pacientes que lograba erecciones con la rigidez suficiente para la penetración fue de 72,80 y $85 \%$ con dosis de 25,50 y $100 \mathrm{mg}$ de sildenafil comparado con el $50 \%$ del placebo $(p<0.001)$. En el de ajuste de dosis el $63 \%$ de los intentos con sildenafil fueron exitosos en comparación con el $22 \%$ con placebo $(p<0.001)$. El promedio de relaciones sexuales exitosas fue 5.9 /mes en los que recibieron sildenafil y $1.5 /$ mes en los que recibieron placebo $(p<0.001)$. Efectos adversos dosis-dependiente y transitorios (6-18\%): cefalea, eritema, dispepsia y rinitis. Más raro alteraciones visuales.

\section{Conclusiones}

El sildenafil por vía oral es un tratamiento efectivo y bien tolerado para hombres con DSE.

\section{COMENTARIO}

La DSE, definida como la dificultad para lograr o mantener un grado de erección suficiente para una relación sexual satisfactoria, es un trastorno muy común que afecta a una gran proporción de hombres. Su prevalencia aumenta con la edad, estimándose en aproximadamente $40 \%$ a los 40 años y acercándose al $70 \%$ en hombres de 70 años. Clásicamente, su etiología se divide en orgánica, psicógena o mixta y su tratamiento ha estado restringido al ámbito del especialista. El presente estudio es el primero que demuestra la eficacia de una droga administrada por vía oral, cuyo mecanismo de acción respeta integramente todos los fenómenos fisiológicos asociados con la erección y el normal desenvolvimiento de la relación sexual. Los pacientes que recibieron sildenafil percibieron diferencias muy importantes tanto en la calidad como en la cantidad de sus relaciones sexuales y esto fue independiente del tipo de DSE que tienen. Las diferencias con el grupo placebo fueron evidentes con 25, 50 y $100 \mathrm{mg}$ y el sildenafil demostró tener un efecto dosis respuesta sugerido por un mayor éxito en la penetración a mayor dosis. Los efectos adversos más comunes fueron transitorios y poco importantes. Los 16 reportes de casos de muerte recibidos por la FDA correspondieron en su mayoría a pacientes con comorbilidad cardiovascular importante y la información disponible no permite atribuir la causa a efectos propios del sildenafil (2). El estudio excluyó a pacientes con patología importante.

Siendo la DSE un trastorno no sólo de quien lo padece sino también de su pareja, y tomando en cuenta que uno de los criterios de inclusión del estudio requería estar en pareja por al menos 6 meses, llama la atención la escasa participación de las mujeres ya que sólo el 25\% devolvió el cuestionario que evaluaba su satisfacción. Sin lugar a dudas, dada la subjetividad de las medidas de evaluación, el estudio se hubiera enriquecido si se contara con esos datos. De todas maneras, esto no altera la conclusión del estudio ya que las características propias del diseño y su implementación sumado a los hallazgos, prueban contundentemente la eficacia de esta droga en el tratamiento de la DSE, al menos durante los 6 meses en que fue evaluada. Como siempre ocurre con un ensayo clínico controlado que prueba la eficacia de un tratamiento, habrá que esperar ahora el impacto real, una vez que se difunda la utilización de la droga en la población general.

\section{Dr. Fernando Rubinstein}

Unidad de Medicina Familiar y Preventiva. Hospital Italiano de Buenos Aires. 